\title{
Application of RFID technology in development of warehouse logistics management system by Internet of things
}

\author{
Hong Qi Hao ${ }^{1, a^{*}}$ and Bin Zhao ${ }^{1}$ \\ ${ }^{1}$ College of Information Technology, Luoyang Normal University, Luoyang,471022, China \\ ahaohongqily@163.com
}

Keywords: Logistics management; RFID; Warehouse; Internet of things; Management system

\begin{abstract}
The RFID module is a combination advanced product of the radio frequency technology and IC card technology. Warehouse logistics management system consists of business management software, RFID label issuance system and RFID tag recognition collection system. This paper analyses the application of RFID technology in logistics warehouse management of each process and each link and presents development of warehouse logistics management system based Internet of things RFID technology. The experimental results show that RFID technology can minimize the cost of storage and improve the efficiency of logistics system effectively.
\end{abstract}

\section{Introduction}

At present, warehouse management systems typically use a bar code label or manual storage management documents and other ways to support their own warehouse management. But the bar code easy to copy, not anti fouling, moisture, complicated operation and other characteristics, and manual writing documents tedious, easy to cause the human loss, so now the storage management of domestic always exist defects. Radio frequency identification (RFID) into the application of this new technology can solve the problem fundamentally. Based on the radio frequency identification (RFID) technology, according to the actual situation and demand of warehouse management, it is warehousing and logistics development of the RFID solution.

In the logistics information system in location management is a very important management, whether static or dynamic position, through RFID technology, can be very good management of goods static location and dynamic location. The terminal is matched with the information system and the RFID handheld, can be in the library shelves links people automatically complete the inventory quantity, position update, avoid artificial error. Shipment can determine whether the goods, whether to take the wrong goods in shipment approval process; RFID reader can read once more tags, greatly improve the correct rate and shipment approval rate selection.

The RFID tag is the data carrier and detection in RFID system [1]. It consists of a coupling element (antenna or coil), micro chip and sensor to form, if it is active or semi-active radio tags should also provide working power supply with battery label. Each tag has its own unique ID number; each container is installed above a label. When the container to load cargo in the port terminal, through wireless or wired way of electronic tag entry goods information, generally including cargo types, quantity, loading and unloading time, and place of loading and unloading destination information.

RFID technology can achieve the tracking products, clear and accurate prediction of inventory in the supply and demand, make inventory is scientific and reasonable, the retailer if improved customer service and satisfaction, its sales will significantly enhance it [2]. The supplier can send the goods type, origin, manufacturers and batches of products such as product details written into the tag, when labeled container through the reader, tag will be product data passed to the reader, reader and then download the data to a central processor, generating enterprises list of goods management database. The paper presents application of RFID technology in development of warehouse logistics management system by Internet of things. 


\section{Solution of warehousing logistics management system}

Warehouse management system is aimed at the enterprise warehouse material receiving, storage, transfer, warehousing and inventory check and other aspects of the work and the development of management software, according to the requirements of enterprises, realize the warehouse receiving management, storage management, moving management and inventory management and user management functions [3]. The user through the corresponding module, the basic situation of the warehouse material to update, delete and query, material on the material receiving, storage, transfer, warehousing and inventory management, query the function of each module in detail, on the use of the system for users to update, delete and query, query on inventory quantity, user through simple can be easily manage warehouse.

Inventory optimal control part is to determine the warehouse business model, namely to (according to the design requirements of a layer) to determine the management objectives and management mode of the warehouse, if supply an executive link chain, is a cost center, much to the quality of services, operation cost as the control target, the pursuit of reasonable inventory even zero inventory. Therefore, accurate understanding of warehouse goods information is crucial to the system, so we proposed to solve storage management accurate.

The goods in the storehouse, first need to input computer goods, library, and computer display immediately shipment bitmap, and the results for the transmission of the list in the form to the handheld reader (Reader) on [4]. The operator through the handheld machine instructions can be found on the goods smoothly, the tray will be installed by hand to pull goods and electronic label reader scan on the tray, and then press the "outbound" button, and the goods on pallets can a library. If the goods on pallets and computer display in a different situation, monitoring the door will be located in the warehouse on either side of the door to sound the alarm. This batch of goods will need to follow the "outbound" process, as is shown by equation (1).

$$
S_{x}(\omega)=\frac{1}{2 \pi} \sum_{k=-\infty}^{\infty} R(k) e^{-j \omega k}
$$

Container transport has good privacy; transport packaging is not damaged, low transportation cost, strong environmental adaptability, high loading density and palletizing normative characteristics. In general, the container by the special container transportation company needs to be provided to transport enterprises to use. After the arrival of the goods and then used by the container recycling companies. In the process of the transportation and the use of container tracking management, the key link is the container and how to prevent container lost, stolen and damaged container, improve turnover rate, and improve the efficiency in the use of resources. In order to achieve the above goals, the company needs the container operation in each link of supply chain of container tracking.

Set $g$ dispatching form. The scheduling process and ship scheduling process set are closely linked. Only in the ship scheduling based on, in order to achieve the set scheduling. The ship scheduling process is typical: from the shipping company commissioned shipping; shipping forecast issued to the port business; business department to assign homework terminal company; the corresponding terminal to the business department to apply for dynamic; business department to the shipping company, wharf, turn off center and other units issued dynamic [5].

$$
I=\left\|{ }^{c} P(k \mid k-1)\right\|-\left\|{ }^{c} P(k \mid k)\right\|
$$

Logistics consists of warehousing, transportation, distribution processing, handling, packaging, information processing and other links, which is indispensable in the storage ring of logistics, and plays an important role in the whole logistics process. Storage is the buffer pool production of raw materials, semi-finished products and finished products, to provide the guarantee for the sustained and stable production, the realization of economic production and transportation. 


\section{Design of intelligent logistics management system based on RFID Technology}

The system application, electronic label is affixed to each package or tray; in the tag write specific data, the storage of goods position information. At the same time in the details of goods import and the warehouse can be written to party, provided with fixed or handheld reader in the warehouse and the distribution of the pipeline, with the identification and detection of circulation of goods. The system can be selectively used for each business link and process of purchase, storage, manufacturing, packaging, loading and unloading, transportation, distribution processing, distribution, sales to service. So that enterprises can timely, accurately grasp the direction and the change of business flow, logistics, information flow and capital flow of the whole supply chain.

Warehouse logistics management system consists of business management software, RFID label issuance system and RFID tag recognition acquisition system, and these systems are related to each other and to complete each process of Warehouse Management Co. The backstage database warehouse management system is the core of the whole system, identification of RFID acquisition is the basis and means of management function, as is shown by equation(3) [6].

$$
\tilde{V}_{j}=\tilde{V}_{J} \bigoplus_{k=0}^{J-j-1} \bigoplus_{\lambda=1}^{3} W_{J-k}^{\lambda}
$$

This paper analyzes the typical application modes of RFID technology in logistics, were analyzed from the aspects of logistics information system, range product logistics mode, third party logistics business model, express business mode [7]. Also a detailed analysis of the composition, process and functions of a logistics warehouse management oriented RFID system.

Application of RFID system is the tray + bar code management RFID and bar code combination, that is to say, the "tag" installed in nearly 100 on a tray, and each item is still "bar code". The RFID series is the static dynamic information using electronic tags to the management of bar code, every process of goods moving by the tag and reader automatic recording, automatic processing. This saves a large portion of the mechanical repetition labor, so now the warehouse management efficiency and accuracy has been greatly improved, as is shown by equation(4).

$$
V_{j+1}^{2}=V_{j} \oplus W_{j}
$$

RFID in the field of logistics management application links although logistics is just one of the application fields of RFID, but RFID technology can combine closely with each link in the supply chain, it is likely to replace the bar code scanning technology in the near future, and will bring revolutionary change to the logistics management [8]. The procurement, storage, packing, loading and unloading, handling, transportation, distribution, processing, distribution, sales and service are an integral part of logistics chain of business process and business process, they are complementary and mutually constraining. In the logistics operation, enterprises must be real-time, accurately understand and grasp the whole logistics links of the business flow, logistics, information flow and capital flow in the four flow and change, make these four kinds of flow and all aspects and all the processes are coordinated and cooperate with each other, so as to play its maximum economic benefit and social benefits [9].

Warehouse logistics installation which is connected with the computer and the computer network of the reader, it will emit radio band artificial adjustment all the time, through the installation of receive antenna in a specific region and read and think, electronic label information can be read, these electronic label attached to the goods surface, antenna also installed in the goods in and out, is generally in the import goods warehouse door, good management of the warehouse.

Inventory management: keeping in a warehouse of goods, it is the fundamental object of warehouse management; inventory according to the form is divided into: pallets, box and bulk three forms, limited to the current RFID is not suitable for management to every small piece of goods, so the use of RFID management objects is FCL and unit the tray (including large single product). 


\section{Application of RFID technology in development of warehouse logistics management system by Internet of things}

RFID warehouse management system consists of business management software, RFID label issuance system and RFID tag recognition acquisition system, and these systems are related to each other and to complete each process of the inventory management in common [10]. According to the specific needs of enterprises, in the raw materials warehouse management system, the use of bar code automatic identification technology and wireless mobile processing technology based on improve warehouse operation efficiency and real-time information processing, so that managers can timely and convenient access to all kinds of material flow information.

This paper respectively from the RFID technology in the logistics warehousing management in each process, each link in the application; in the light of various problems existing storage management, construction of intelligent logistics warehouse management system; realize the high efficiency of warehouse logistics warehouse management and in the storehouse and other business management; and on the Internet of things applications in logistics warehousing system of the experimental study, as is shown in Figure. 1

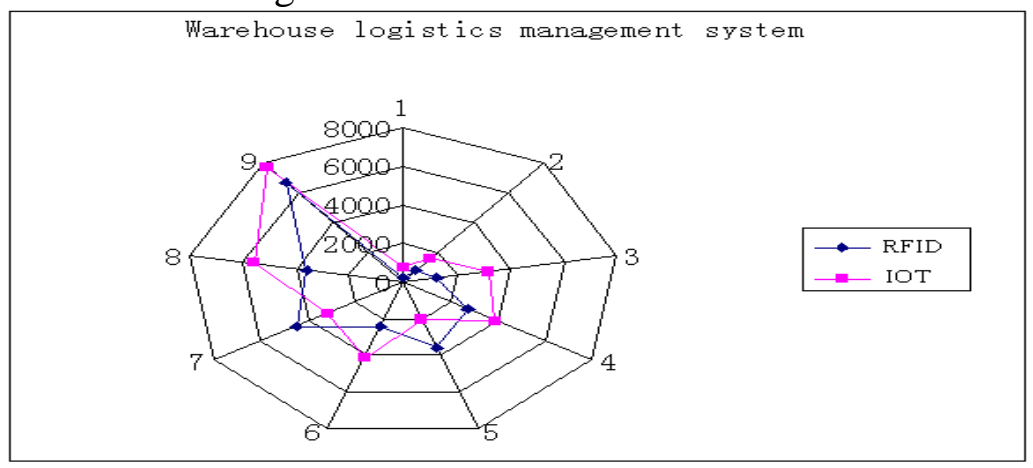

Figure. 1 Development of warehouse logistics management system by Internet of things with RFID

The RFID technology makes the reasonable product inventory control and intelligent logistics technology become possible. By means of radio frequency label, can be realized commodity on the raw materials, semi-finished products, finished products, transportation, warehousing, distribution, shelves, final sales, real-time monitoring and even return processing chain.

\section{Summary}

Introducing RFID technology in warehouse logistics management system in each link of enterprise inventory management, can achieve the automation of data collection more, function control. Workers can do not have to perform data acquisition in the work at the same time action, can put his whole heart into production, so the work efficiency is improved.

\section{References}

[1] SunYu Jie, Julian Clive, "Research of Logistics Product Intelligent System Distribution Based on Internet of Things", JDCTA, Vol. 7, No. 6, pp. 979 986, 2013

[2] Wei Lifeng, Ji Jianwei , Xu Jiawang, "Research on the Production Logistics Information Terminal Based on RFID Technology", JDCTA, Vol. 6, No. 20, pp. 114 121, 2012

[3] Keke Chen, Guohong Gao, "Using Agent and Swarm Platform to Construct Logistics Simulation System", JCIT, Vol. 8, No. 5, pp. $454 \sim$ 463, 2013.

[4] KeeHyun Choi, KyungSoo Jang, HoJin Shin, "Content Self-Protection for Digital Products Using RFID-enable Agent Platform", IJEI, Vol. 2, No. 2, pp. 43 53, 2011 
[5] JIAO YABING, "Construction and Application of Logistics Information Tracking System Based on RFID Technology", JCIT, Vol. 8, No. 10, pp. $837 \sim$ 845, 2013.

[6] Dae-Man Do, Maeng-Hwan Hyun, Young-Bok Choi, "RFID-based Indoor Localization for Emergency Rescue Evacuation Support", AISS, Vol. 5, No. 16, pp. 77 85, 2013.

[7] DOU Xue-xia, "The Building of University Assets Information Management System based on RFID", IJACT, Vol. 5, No. 2, pp. 289 297, 2013.

[8] Zhen Wu, Jin Peng, "A Chance-constrained Model of Logistics Distribution Center Location under Uncertain Environment", AISS, Vol. 6, No. 3, pp. 33 42, 2014

[9] Xian-xian BU, Yan-zhao LI, "The Development of The Enterprise Logistics Management Information System based on UML", IJACT, Vol. 4, No. 16, pp. 304 311, 2012

[10] Wei Li, "Research on Logistics Financial Credit Evaluation of Third-Part Logistics Enterprises with Uncertain Information", AISS, Vol. 4, No. 8, pp. 171 177, 2012 